\title{
The impact of language barrier and communication style in organizational culture on expatri- ate's working performance
}

\author{
S.N. Ramlan*, A. Abashah, I.H. Abu Samah, I.M. Abd Rashid and W.N. Wan Muhamad Radzi
}

School of Business Innovation and Technopreneurship, UniMAP, Malaysia

\begin{tabular}{l}
\hline C H R O N I C L E \\
\hline Article history: \\
Received: November 26, 2017 \\
Received in revised format: Janu- \\
ary 31,2018 \\
Accepted: April 7, 2018 \\
Available online: \\
April 8, 2018 \\
\hline Keywords: \\
Organizational culture \\
Language barrier \\
Communication style \\
Expatriate's working perfor- \\
mance
\end{tabular}

A B S T R A C T

\begin{abstract}
This research explores the impact of organizational culture on expatriate's working performance at Universiti Malaysia Perlis. The factors that affect expatriate's job performance are important in enabling expatriates to acquire essential competencies that allow them to complete their tasks in workplace. This research was a survey (questionnaires) method. Data were gathered from 150 respondents consist of expatriates who were academicians and non-academician of legal age 18 and above on random basis from several academic schools in UniMAP. The analysis of the study uses Microsoft Excel and Statistical Package for Social Sciences (SPSS) Software Version 16.0. The data were analyzed using descriptive analysis and multiple regression analysis. According to the results presented, language barriers and communication style were found to have significant effects on expatriate's working performance. Therefore, from the results of two hypotheses tested there are meaningful relationships between language barriers and communication style toward expatriates working performance at Universiti Malaysia Perlis. This research has accumulated an empirical knowledge base which concentrates on coping behaviors for foreign staffs in higher education institution contexts. The findings of this research will help the management of UniMAP understand the impact of organizational culture's factors on expatriates working performance. The results of the present study showed that it could set up the right organizational culture and ultimately further improve the organization performance.
\end{abstract}

\section{Introduction}

Culture is often defined as a system of shared values, beliefs, and attitudes that influences individual perceptions, preferences, and behaviors. Culture is one of the factors that will influence employees working performance in organization especially for expatriates. Culture difference will influence the expatriates on certain way of doing things like complete tasks or interact with each other members in an organization. It is importance for a leader in an organization to understand the role of culture in his working place. Culture of different countries can be one of the factors of determination of a staff's working performance especially for expatriates. In an organization, larger culture difference will requires stronger controls of manager in the organization, fail of manager to understand the importance

* Corresponding author.

E-mail address: izleen@unimap.edu.my (S.N. Ramlan) 
of culture will cause problem in the organization. Failure to understand the difference in culture may lead to embarrassing, broken of relationships, and give impact to the business performance in organization (Ghemawat \& Reiche, 2011).

Elements of culture can be described as exchanging operating processes, habits, etc. about sampling the environment, and the like of the person (Triandis \& Suh, 2002). Another definition of culture is "culture is a society identifies to an individual". Culture includes the experience and knowledge of a person on the society, and this knowledge is transmitting to future generations (Triandis \& Suh, 2002). The expansion of international corporations increases the necessary of manager to deal with cultural diversity and teams consisting of employees of different nationalities with difference cultures (Przytuła, 2014). The differences of nationalities and culture cause different working style in one organization. The cooperation of expatriates with local employee will bring confluences in working place because expatriates have difference working style with local employee.

The aim of the research is to investigate the influence of culture differences to expatriates working performance particularly language barrier and communication styles. This study will focus on the expatriates at University Malaysia Perlis. Culture will influence the way to perform in working either positively or negatively. This paper defines and elaborates on the construct of the language barrier and communication style, a construct which is believed to be helpful for further research on the impact of cultural differences in managing expatriates. By looking at university management and comparing expatriates behavior across a range of cultures, this research has accumulated an empirical knowledge base which concentrates on coping behaviors for foreign staffs in higher education institution contexts. However, as few of these studies have placed cross-cultural communication into the context of the broader setting, it would appear that the implications of communication barriers, and more specifically language and communication style, for higher education institution have been relatively ignored. Therefore, it would seem appropriate to examine in greater depth the role of language and communication style and its effects in terms of control and coordination in managing expatriates.

\section{Literature Review}

\subsection{Culture}

Culture is the integrated sum total of learned behavioral traits shared by members of a society (Deari et al., 2008). However, Wang et al. (2009) defined culture as "patterns of beliefs and values that are manifested in practices, behaviors, and various artifacts shared by members of an organization or a nation". Culture influences what social norms individuals recognize and what behaviors they believe they should or should not perform. Whereby, cultural in work values differences that is influenced by culture can give effect on individual performance and to predict job satisfaction in work place (Matić, 2008; Shafiq \& Qureshi, 2014; Zaman et al., 2011).

Therefore, these differences from one culture to another one and from a person to another one bring differences in working style as individuals have different values and different preferences with regard to working style that are related to their cultural background. Determining the culture values of employee is an important part. Culture values of employees will affect their working style in many ways, from body language, communication style, time management and problem solving. Consequently, it is important for the management to understand employee culture differences that will give benefits them in terms of negotiation, developing effective reward systems, develop management style, easy to facilitate communication and ultimately give a positive impact to the overall organizational performance. 


\subsection{Language Barrier}

Language is the key to a person's self-identity. It enables the person to express emotions, share feelings, tell stories, and convey complex messages and knowledge (Kim \& Mattila, 2011). Communication is the exchange of meaning, when there is a language barrier; effective two-way communication becomes even more difficult (Adler, 1991; Rabbani et al., 2017). Language is a very important issues in managing expatriates (Rubin \& Rubin, 2011). Moreover, language provides a significant frame of reference and a relational context that can representative a person's identity. Therefore there are differences in language cause by culture difference in expatriates. Understanding of the relationship between language barriers and social identity patterns of an expatriate is important to determine the work performance. Language barriers are a common challenge when working with expatriates. What native speakers often do not realize is that frequently it is not the other person's accent but their own way of speaking that creates the greatest barriers to effective communication (Berardo \& Deardorff, 2012; Javadpour \& Samiei, 2017).

Language barriers often go hand-in hand with cultural differences, posing additional problems and misunderstandings in the workplace (Morris, 2002). Thus, language barriers can easily give impact in the work performance because messages can easily be misconstrued. Language barriers way affect an expatriate's performance in many aspects. The research states that $65 \%$ company faced the problem of language barriers existed among their companies' managers/executives and other workers and $67 \%$ of the respondents said that miscommunications were leading to inefficiency and more than $40 \%$ noted that miscommunication made collaboration difficult, and a similar percentage noted that productivity was lower than it should be due to language barriers (Rubin \& Rubin, 2011). These results show the impact of these barriers may be significant. Language barriers cause difficulties of expatriates to communicate with other workers, lack of communication could lead to lower productivity of worker.

\subsection{Communication Style}

Communication is the use of messages to produce meaning between two or more people. Culture will give impact on communication style in verbal \& nonverbal communication. Communication includes sending both verbal messages (words) and nonverbal messages (tone of voice, facial expression, behavior, and physical setting) (Boyacigiller \& Adler, 1991). It includes sending messages that the sender is unaware of sending (Boyacigiller \& Adler, 1991). Verbal communication is the sharing of information among individuals by using speech. Effective verbal communication needs a clear understanding of spoken words, stress and tone of voice with which the words are expressed is appropriated. Nonverbal communication includes body language such as facial expressions, eye contact, and tone of voice. Non-verbal communication is one of the essential parts in communication process, which is different from culture to another.

Communication can be an indirect action and is a symbolic behavior. Ideas and feelings cannot be communicated directly but has to be symbolized before being communicated (Boyacigiller \& Adler, 1991). Each culture has its own characteristics, which affect verbal and nonverbal in communication process. For example, by looking at the other people's eyes when communicate. These characteristic are difference from one culture to another. Among others: small talk, body language, eye contact, personal space and touching. Miscommunications can be caused by cultural differences in body language and other behaviors. Each culture has its own understanding for a same action. Culture influences the communication style in different cultural values, attitudes and beliefs, which is one category that descript on misunderstanding between cultures. 


\subsection{Research Hypotheses}

Hypotheses have been developed for this study is based on dependent and independent variables at follows:

- H1: There is a significant relationship between language barriers and expatriates working performance in University Malaysia Perlis.

- H2: There is a significant relationship between communication styles and expatriates working performance in University Malaysia Perlis.

Fig. 1 shows the structure of the proposed study.

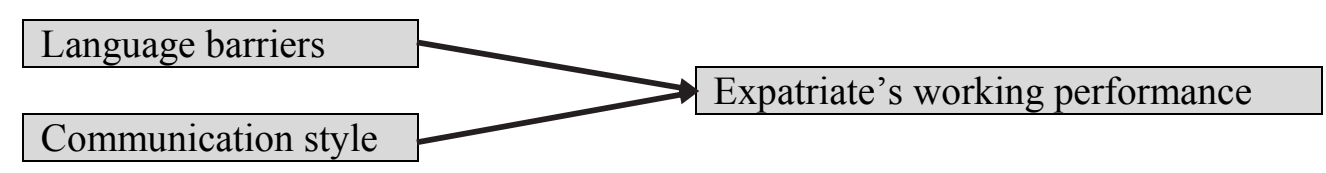

Fig. 1. Theoretical Framework

\section{Methodology}

The population of this study includes expatriates at Universiti Malaysia Perlis (UniMAP). Unit analysis of this study is individual. There are 150 expatriates selected randomly from various academic schools in UniMAP. Respondents were of legal age 18 and above. Stratified samplings were adopted in order to get more accurate results, which reflect the population of this study. The research applied a quantitative method and conduct data collecting through survey questionnaires using 5-likert scale. Questionnaires were previously developed from past researchers. The data analysis of this study used Microsoft Excel and Statistical Package for Social Sciences (SPSS) Software Version 16.0 program for Windows. The data were analyzed using descriptive analysis and multiple regression analysis. The questionnaire consists of three questions to measure the organizational culture factors. All measurements are standardized to a five-point scaled, with 1 being 'strongly disagree' and 5 for 'strongly agree'.

\section{Results and Findings}

Frequency and percentage were used to indicate generally the distribution of the profile in respect to the respondents. It presents the results of the survey on culture differences which influence expatriates working performance at UniMAP. The culture differences include language barrier and communication style. The first section of the questionnaire survey stated the respondent's profile. Therefore, goodness of measures was examined by using factor analysis and reliability analysis. In the next section, which provides the inter correlation between all the variables that are studied and descriptive statistics that showed the mean and standard deviation of the factors considered.

\subsection{Overview of Data Gathered}

Table 1 indicates the sample profile from questionnaire survey. There were 150 questionnaires distributed among selected respondents randomly. However, only 132 questionnaires were collected back. These made up $96.2 \%$ of total questionnaires distributed were satisfactorily completed and tested using the Statistical Package for Social Sciences (SPSS) software. 
Table 1

Response Rate

\begin{tabular}{lc}
\hline Number of Questionnaires Distributed & 150 \\
Number of Questionnaires Collected Back & 132 \\
Response Rate & $88 \%$ \\
Number of Questionnaires Used for Analysis & 132 \\
\hline
\end{tabular}

\subsection{Data Presentation}

Fig. 2 summarizes all the demographic data of the respondents including gender, age, marital status and time service in UniMAP. From 132 respondents, the results indicated that there were more female with $56.1 \%$ than male ones. The majority of 132 respondents aged between $30-40$ years old (40.2\%), $37.9 \%$ of respondents were $40-50$ years old consisting 50 respondents, $14.4 \%$ of respondents were 20 - 30 years old consisting 19 respondents and $7.6 \%$ of respondents were 50 and above years old consisting 10 respondents. The results show that $77(58.3 \%)$ of the respondents were married and the remaining $55(41.7 \%)$ are single. As for the time service at UniMAP, $44(33.3 \%)$ of the respondents were service at UniMAP for $1-3$ years, $28(21.2 \%)$ of the respondents were service in UniMAP for less than 1 year and it is same for the category $1-3$ years. Lastly, $32(23.2 \%)$ of the respondents were service in UniMAP for more than 5 years.

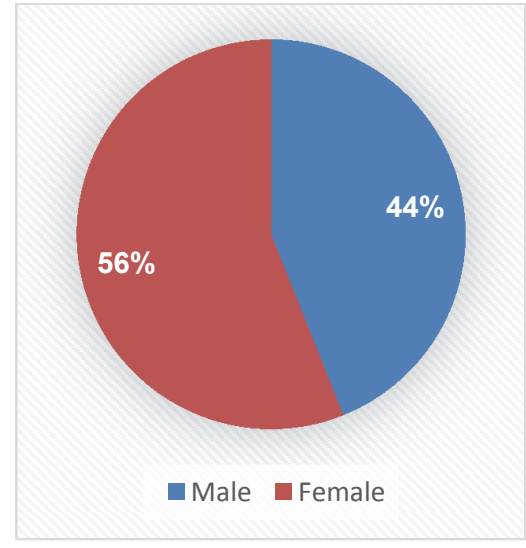

Gender

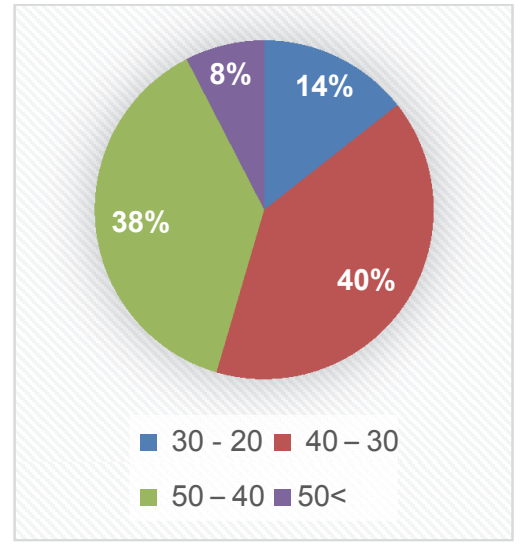

Age

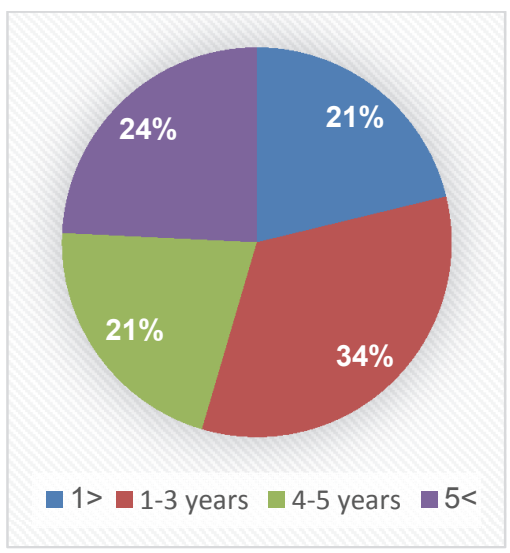

Time service in UniMAP

Fig. 2. Personal characteristics of the participants in the survey

\subsection{Results}

\subsubsection{Descriptive Analysis}

Table 2

Results of Descriptive Analysis

\begin{tabular}{lccccc}
\hline Factors & $\mathrm{N}$ & Min & Max & Mean & Standard Deviation \\
\hline Language Barriers & 132 & 2.40 & 5.00 & 3.9106 & 0.49072 \\
Communication Style & 132 & 2.40 & 5.00 & 3.9439 & 0.41522 \\
\hline
\end{tabular}

According to Table 2, mean for all variables ranges between 3.9106 and 3.9439. The mean of independent variables measures which are language barriers and communication style. Meanwhile, for standard deviation the rate is between 0.41522 and 0.49072 . Finally, for the highest mean is Communication style with 3.9439 and for the highest standard deviation is language barrier which is 0.49072 . 


\subsubsection{Regression Analysis}

Table 3

Results of Regression Analysis

\begin{tabular}{lccc}
\hline Variables & Beta & t-Ratio & Sig. t \\
\hline Language Barriers & 0.232 & 2.116 & 0.036 \\
Communication Style & 0.537 & 4.215 & 0.000 \\
\hline
\end{tabular}

According to the results of Table 3, language barriers have significant at (sig. $t=0.036$ ) with a positive beta towards the expatriate's working performance. Next, communication style also was found to have significant effect on expatriate's working performance with (sig. $\mathrm{t}=0.000$ ) with a positive beta towards the expatriate's working performance. Therefore, from the results of all hypotheses tested stated that there are relationship between language barriers and communication style toward expatriates working performance at Universiti Malaysia Perlis which supported at the significance level of $\mathrm{p}<0.05$.

Hypothesis 1 examined the relationship between language barriers and expatriate's working performance at University Malaysia Perlis and this hypothesis was accepted. Language acts as medium that allows two people to communicate with each other in communication process. If two people cannot speak the same language, they have to use translation in communication, this increases the potential for misunderstandings. Misunderstanding will bring the effect problem to the person involved and more even likely to influence their work performance.

Hypothesis 2 examined the relationship between communication style and expatriate's working performance at University Malaysia Perlis and this hypothesis was accepted. Communication is the use of messages to produce meaning between two or more people. Each culture has its own characteristics, which can affect the verbal and nonverbal in communication process and people from different cultural background also have their own understandings about verbal and nonverbal messages. Failure to send messages clearly between both parties will cause misunderstanding and bring effect to their work performance.

\section{Conclusion}

The results of this study indicate that it is important for management of UniMAP to be discerning regarding the culture difference among expatriates. It helps management of UniMAP to have better understanding of the factor influencing on working performance of their staffs. Cultures play an important role in determining the working performance of the expatriates. The influence of the culture on human beings will bring difference in working performance. Thus, it is important for UniMAP management to develop effective management strategy in controlling and coordinating the expatriates in order to achieve better working performance for overall organizational excellence.

\subsection{Limitations of the Study}

This study has limitations since the results might be biased. This is because the data obtained may not be a total representative of the changes that occur at the University Malaysia Perlis (UniMAP). The samples were limited to selected staff in UniMAP. In addition, respondents may not be an accurate representation of the staff context as a whole since the study was based on only 132 respondents. However, it should be emphasized that the larger the sample size, the more representative results from the analysis. Moreover time constraint was another limitation of the present study. 


\subsection{Suggestions for Future Research}

Concerning recommendations for future research, all the limitations of the present study as stated above should be overcome. Future researches are recommended to develop a better model and expand their population in order to represent the UniMAP's expatriate's context. Future researches are highly recommended to select respondents from all the school in UniMAP. This will give a clear and better scenario on how culture difference influence expatriates working performance in UniMAP. Due to time constraint, the data collected may not be comprehensive. Therefore, more time should be allocated for this research.

Another scope of the research would be to move the level of analysis from a university to an industry of higher education institutions. For example, in the aviation industry, English is used as a standard language: yet there is anecdotal evidence suggesting those pilots' and traffic controllers' limited skills in English have contributed to serious accidents. Given the importance of language skills, several airline companies provide their staff with language training; for example, the Dutch airline company KLM (ten Zijthoff, 1997). Obviously, the issue of the language in the broad cross-cultural context provides several interesting and challenging research paths that might be followed.

\section{Acknowledgement}

The authors would like to thank the anonymous referees for constructive comments on earlier version of this paper.

\section{References}

Berardo, K., \& Deardorff, D. K. (2012). Building cultural competence: Innovative activities and models: Stylus Publishing, LLC.

Boyacigiller, N. A., \& Adler, N. J. (1991). The parochial dinosaur: Organizational science in a global context. Academy of Management Review, 16(2), 262-290.

Deari, H., Kimmel, V., \& Lopez, P. (2008). Effects of cultural differences in international business and price negotiation. In.

Ghemawat, P., \& Reiche, S. (2011). National cultural differences and multinational business. Globalization note series, 11, 1-18.

Javadpour, A., \& Samiei, S. (2017). Motivation and barriers to participation in virtual knowledge-sharing communities of practice. Management Science Letters, 7(2), 81-86.

Kim, E. E. K., \& Mattila, A. S. (2011). The Impact of language barrier \& cultural differences on restaurant experiences: A grounded theory approach.

Matić, J. L. (2008). Cultural differences in employee work values and their implications for management. Management: Journal of Contemporary Management Issues, $13(2$ (Special issue)), 93-104.

Morris, F. A. (2002). Negotiation moves and recasts in relation to error types and learner repair in the foreign language classroom. Foreign Language Annals, 35(4), 395-404.

Przytuła, S. (2014). Intercultural interactions in the German subsidiary operating in Poland-a case study. Journal of Intercultural Management, 6(3), 73-89.

Rabbani, M., Farrokhi-Asl, H., \& Manavizadeh, N. (2017). Using Robust-DEA optimization approach to analyze performance and efficiency of a mine in north of Iran. Management Science Letters, 7(2), 97-110.

Rubin, H. J., \& Rubin, I. S. (2011). Qualitative interviewing: The art of hearing data: Sage.

Shafiq, M., \& Qureshi, M. I. (2014). Quadruple culture type approaches impacting employees attributes. Journal of Management Info, 2(1).

ten Zijthoff, J. (1997). Phone conversation with KLM representative for Corporate Education, language training. International Business Review. 
Triandis, H. C., \& Suh, E. M. (2002). Cultural influences on personality. Annual review of psychology, 53(1), 133-160.

Wang, H.-C., Fussell, S. F., \& Setlock, L. D. (2009). Cultural difference and adaptation of communication styles in computer-mediated group brainstorming. Paper presented at the Proceedings of the SIGCHI Conference on Human Factors in Computing Systems.

Zaman, K., Qureshi, M., \& Bhatti, M. (2011). The impact of culture and gender on leadership behavior: Higher education and management. Management Science Letters, 1(4), 531-540.

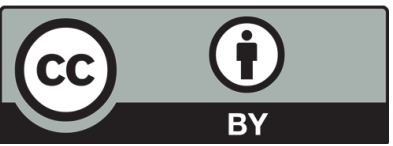

(C) 2018 by the authors; licensee Growing Science, Canada. This is an open access article distributed under the terms and conditions of the Creative Commons Attribution (CC-BY) license (http://creativecommons.org/licenses/by/4.0/). 